\title{
HOW EVIDENCE-BASED DESIGN SUPPORTS BETTER VALUE GENERATION FOR END-USERS
}

\author{
Y. Zhang ${ }^{1}$, P. Tzortzopoulos ${ }^{2}$, and M. Kagioglou ${ }^{3}$
}

\begin{abstract}
Interest in evidence-based design (EBD) has been growing extensively. Proper design decisions can, not only maximise the occupants' health benefits, but also, improve service delivery. There is a clear link between the concept of EBD and that of value generation to guide decision-making for better healthcare design. Through an extensive literature review, a conceptual framework is presented, illustrating important decision-making steps, considering EBD as a means, with an emphasis on how it helps increase the end-user's value generation. The paper concludes by identifying limitations and potential future studies.
\end{abstract}

Keywords: value, healthcare building, evidence-based design

\section{INTRODUCTION}

A growing body of evidence indicates that physical environment affects patient and staffs well-being, healing processes, stress reduction, safety and quality of care provided in healthcare buildings. Basing healthcare design decisions on this evidence and generating actionable advice to achieve the best possible patient, staff and operational outcomes, is what evidence-based design (EBD) is all about. However, information on the effect of the built environment on end-users' health and well-being is still very limited and difficult to establish, especially as regards how well a positive environment could be. It seems premature to formulate EBD guidelines for decision-making and is an area in need of further research (Tzortzopoulos et al.,2005, Dijkstra and Pieterse 2006).

This paper explores how EBD supports better value generation for end-users. It is structured as follows: it begins by describing value in general and healthcare building specifically in literature and practice, followed by interpreting the research problems and method. The paper goes on to present the review findings, illustrating important steps used for decision-making in a given setting when using EBD as an intervention, with an emphasis on how EBD helps increase end-user generation. The paper concludes by identifying limitations and potential future studies.

\subsection{Value in Healthcare Buildings}

Improving performance depends on having a shared goal that unites the interests and activities of all stakeholders. In most fields, the pre-eminent goal is to reach the best possible value from the point of view of the customer (Shewhart, 1931). Nowadays, the emphasis on 'value' and how it can be generated and maximised, is growing in

\footnotetext{
Research fellow of School of Arts Design and Architecture, University of Huddersfield, Huddersfield, HD1 3DH, UK, +44 1484471 632, y.zhang2@hud.ac.uk

2 Head of Department of Architecture, School of Arts Design and Architecture, University of Huddersfield, Huddersfield, HD1 3DH, UK, +44 1484472 281, p.tzortzopoulos@hud.ac.uk

3 Dean of School of Arts Design and Architecture, University of Huddersfield, Huddersfield, HD1 3DH, UK, +44 1484472 289, m.kagioglou@hud.ac.uk
} 
popularity. One of the essential issues is how to define and measure it (Koskela, 2000). For example, 'value' in project management can be defined as meeting the original design within cost, schedule and quality limits (Koskela et al., 2002). According to Zeithaml (1988), 'perceived value' is the consumer's overall assessment of the utility of a product, based on perceptions of what is received and what is given.

In healthcare, stakeholders have myriad, often conflicting, goals, including access to services, profitability, high quality, cost containment and safety (Porter, 2010). Achieving high value for end-users (patients) becomes the overarching goal of healthcare delivery; as value improves, patients, providers and suppliers can all benefit while the economic sustainability of the healthcare system increases (Porter, 2010). Within this context, value can be something tangible, such as recovery time, staff absenteeism, medical errors, falls, budget plans, service costs, energy consumption and so forth. For example, Walch et al. (2005), found that patients staying on the bright side of the hospital unit ( $46 \%$ higher-intensity sunlight exposure on average) took $22 \%$ less analgesic medication per hour and had $21 \%$ less pain medication costs. Raanaas et al. (2012), carried out a longitudinal quasi-experiment and found a blocked window view appeared to negatively influence changes in physical health for women and mental health for men $(\mathrm{p}<.05)$, when compared to the patients who were assigned to the room with a panoramic view.

On the other hand, the value can also be intangible, such as comfort, satisfaction, quality of sleep and working efficiency. In fact, patients are particularly affected by the intangible aspects of the building. For example, Kaldenberg (1999), discovered that patients in private rooms were more satisfied with their hospital stay, including their communication with staff members, than were patients staying in multiple-occupancy rooms. Freedman et al. (2001), concluded, in a review of current knowledge about sleep in the ICU, that noise was a notable contributor to sleep disorders.

It can be seen that value is measured by outputs, not inputs (Koskela, 2000). Hence, value in healthcare depends on the actual patient health outcomes because it is what ultimately matters for customers (patients) and unites the interests of all system actors (Porter, 2006). Like Stichler once argued, healthcare building is: "A physical setting ... that supports patients and families through the stresses imposed by illness, hospitalization, medical visits, the process of healing ..." (2001).

\subsection{Summary and Focus of this Paper}

From the introduction and a brief review above, it can be anticipated that: (i) the value generation process needs to identify effective and efficient design solutions so that the customer's perception and experience are optimized; (ii) the built environment of healthcare building can, not only maximize the occupants' health benefit (Salonen et al., 2013) but also, improve the service delivery (Grazier, 1999). This research is an attempt to link the concept of EBD, and that of value generation, to guide decision-making for better healthcare design.

This paper acts as a follow-up to initial preparatory work (Zhang et al., 2016). Through an extensive literature review, two research questions are addressed: (i) How can EBD be used to support design decision-making? (ii) What is the value of EBD from the patient's perspective? In other words, what does it bring to the end-users of healthcare building? The purpose of this paper is to identify the starting point of these two research questions and to establish the vision to which the questions are directed. 


\section{METHOD}

A synthesis of the literature is performed to explore current research on EBD with respect to process (evidence generation) and output (value generation). It was carried out, not only to collect the evidence that relates to value generation, but also, to explore how practical options/interventions help increase the value generation. The literature search employed a three-step strategy. Firstly, a wide range of key words and phrases associated with healthcare, building and environment and user experiences were identified from a framework initially built up from previous work (Zhang et al., 2016). Then, the evidence was reviewed by seeking detailed descriptions of how the studies were carried out and how their key findings contributed to value generation. By reviewing the EBD process and output, a conceptual framework was developed to facilitate decision-making in terms of supporting it. In total, 30 papers, reports and books (seven review papers) written in English were included in this paper. It has to be mentioned that this review focused on 'how well a positive environment' can contribute to health benefits, therefore, the evidence of negative impact (e.g. noise) was not included.

\section{RESULTS AND DISCUSSION}

\subsection{Framework}

Figure 1 establishes the links between design decision-making (EBD means) and value generation (value output) in a given setting/project by illustrating how EBD can be applied to support design decision-making with four steps. Firstly, when evidence is identified as a potential for implementation, collecting relevant sources available will be very important, to not only accurately reflect the most up-to-date information, but also, to reduce bias and acknowledge uncertainty. Nowadays, the evidence that supports healthcare building design has been accumulated extensively from scientific research, statistics and many other sources being used in practice. The Cochrane Database of Systematic Reviews (CDSR), Pubmed (Medline), Jstor and Scopus are a few common databases used to find relevant information.

EBD draws on knowledge from a multitude of disciplines with varying approaches to knowledge generation and therefore, it is difficult for implementation in practice due to the different level of credibility and also the fact that not all of the design elements collected are equally positive (step 2). This has also been discussed by a few previous studies using a different approach. For example, Pati (2011), proposed a framework for evaluating the degree of credibility of a specific (or a body) of evidence, separating the strength and quality from the evaluation of appropriateness and feasibility in a specific application context. The assessment of the evidence's credibility will help the stakeholders understand it and treat it with a different level of confidence, avoiding the inappropriate usage (DiCenso et al., 2009).

As most studies attempt to develop one specific evidence to address specific health outcomes, it is important to realise that the benefits generated from EBD depend on how it is applied. The evidence synthesization (step 3) will create a new understanding of EBD by analysing findings from different sources of evidence, with a focus on the same topic of interest, and integrate the best evidence that fits into a given situation (Popay, 2005). A few works also explored the potential solutions to create a manageable framework that integrates varied design features together, for example, Durmisevic and Ciftcioglu (2010); Rybkowski and Ballard (2008). Special attention has to be paid to those 
conflicting evidences, for example, in the current debate of physical size, is bigger better? The implementation has to be carefully considered in the given setting/project.

The central part of this framework in this paper is the 'value generation' analysis (step 4) which is an essential tool for the early design stage when developing an EBD implementation. It is obvious that the more valuable a piece of evidence, the more confidence one has in the findings for application in building and environmental design, regardless of its source: scientific journal and/or practice. To clarify it, the next section assesses the current state of development in detail.

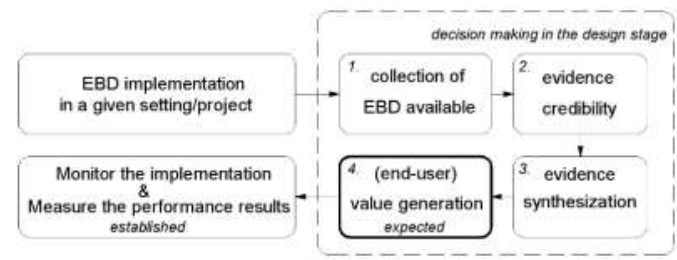

Figure 1: links between design decision-making (EBD means) and value generation (value output)

\subsection{End-users' Value Generation}

The findings of the literature review were organized with the same structure in the following format: EBD foci were firstly categorized into four groups that relate to endusers' experiences when they are in the immediate building space. How EBD adds value for the end-user is also presented in brackets: [a] Improves patient safety and stress level; [b] Improves staff working efficiency and reduces staff turnover; [c] Decreases the need for medication and length of stay; [d] Promotes efficient workflow and quality care. Practical options are then specified with a number from I to IV indicating the level of credibility: [I] systematic review; [II] experimental studies; [III] quasi-experiential studies; [IV] consensus and expert opinions, followed by a few relevant case studies that could link EBD and value generation for the end-users.

Positive Perception [a, c] $\rightarrow$

Links to nature [II III]: Indoor courtyards and atria with greenery (Dijkstra et al., 2008); window view of natural scenery (Raanaas et al., 2012) and well-designed gardens with easy entry, sitting areas (Cooper-Marcus and Barnes, 1995) provide calming and pleasant views of nature which is effective and beneficial for stressed patients and staff.

Natural light [II III]: Large glazing area without obstruction allows the room to receive abundant daylight. Patients had shorter hospital stays when receiving abundant daylight (Raanaas et al., 2012) and took less medicine (Walch et al., 2005).

Colour and art [III IV]: Calming and restoring colours (e.g. blues, greens and violet) (Fontaine et al., 2001); art content (e.g. blue waterscapes, green landscapes) (Daykin et al., 2008) are recommended for high-stress areas and also, areas that require concentration and visual acuity.

Manual control [IV]: Patients have a choice with manual control of room temperature, ventilation rate, lighting level and/or sound when these fall into unacceptable levels (Ulrich et al., 2008). This will be an efficient way to give a familiar and less overwhelming feeling to patients.

Privacy [III IV]: High level of privacy and confidentiality improves communication efficiency (Kaldenberg, 1999), infection control and satisfaction (e.g. single patient rooms) (Kirk, 2002). Patients perceive significantly less auditory and visual privacy in areas with curtains, compared to a room with solid walls (Barlas et al., 2001). 


\section{Flexibility usage $[\mathrm{b}, \mathrm{d}] \rightarrow$}

Nursing station [III IV]: The 'hybrid' nursing station may strike a balance between the increase in computer duties and the ongoing need for communication that addresses the conflicting demands of technology and direct patient care (Zborowsky et al., 2010).

Personalized functional zone [III IV]: It provides a certain level of flexibility for alternative activities and service efficiency (e.g. family zone) (Douglas and Douglas, 2004) breakout area for nurses (Sheahan et al., 2016) and therapy garden (Marcus and Barnes, 1999).

Patient room [III IV]: Single patient room (NHS Estates, 2005) acuity-adaptable rooms (Hendrich et al., 2004) improve the flow of patients and delivery of care. However, few reliable studies were found to evaluate the value of single patient rooms thoroughly (Glind et al., 2007).

Accessibility [a, c, d] $\rightarrow$

Location [IV]: A well-structured path, clear and few choices in navigation (Carpman \& Grant, 2002), unique identification at each location and abundant area for car park (Arthur \& Passini, 1992) can improve the overall user flow.

Signage [III IV]: Typography, colour, pictograms and icons are all elements that can be used in order to offer as much information as needed (Uebele, 2007).

Closeness [IV]: Delivering healthcare services closer to home and nearer to people, alongside work on other solutions, avoids emergency admissions to acute hospital, for example, health and social care centres, community care centres and specialist care centres (Monitor, 2015)

Facilities and Maintenance $[\mathrm{a}, \mathrm{b}] \rightarrow$

Surface [II III]: Carpets reduce falls, resultant injuries, noise levels and glare disturbance (Crane et al., 2014) while hard materials (matte, vinyl-covered surfaces) are easy for maintenance and cleaning (CDC and HICPAC, 2003). Soft flooring is more costeffective for initial purchase and installation, equipment assets and maintenance over the time of facilities (Harris \& Fitzgerald, 2015).

Ergonomics [I]: Ergonomic chairs and desks, adjustable and movable furniture reduce falls, back pain, and increase social interaction (Ulrich et al., 2008). Incidence of falls is improved by reducing the design faults, for example, slippery floors, inappropriate door openings, poor placement of rails and accessories and incorrect toilet and furniture heights (Springer, 2007).

Mechanical control [I]: Mechanical ventilation provides a comfortable environment by controlling the air movement, dust, smell, relative humidity and air quality, which reduces the infection risk that is spread through airborne transmission (Li et al., 2007).

This section first presented a framework indicating an information flow from design decision-making (EBD means) to value generation (value output). Each step of this process has its own respective challenge. For example, when it comes to collecting available EBD, attention should be paid to ensure the 'databases' used are kept up to date Centralizing the data means that only one location has to be searched and managed. As evidence is from multi-dimensional perspectives, and its credibility is varied due to the approaches used to generate knowledge, the assessment of evidence is not only about the strength of credibility but also, about how applicable it is to a specific context. Though research and studies have made an effort to contribute to the richness of the data, there are still questions regarding existing and new pieces of evidence integration. How do we manage the complexities of evidence from different aspects and its relationship in a coordinated way? This is a serious issue which could make it difficult to implement, as the value may become unpredictable when decision-making is restricted to a specific context. 
For example, will the value be enhanced or compromised when taking into account the interactive and correlated effect along with other factors or, when its applicability is in another culture or region, with different healthcare or economy systems? Strategies are needed to best ensure these elements are considered at an early design stage. Furthermore, when the value generation from the EBD process is expected, the implementation reaches its very core: monitoring in an appropriate way (e.g. collect baseline performance measures) so the performance results can be measured. It allows for determining if EBD is implemented with good output (value generation). If not, it allows for taking corrective measures while implementation is in progress. It is expected that new insights will appear during this monitoring process. In this way, EBD means and value outputs are both being further validated and expanded. Another exploration of this conceptual process will be taken to evaluate whether it is right.

\section{LIMITATION AND CONCLUSIONS}

The evidence base in healthcare design is not yet comprehensive enough to support all decision-making contexts. This paper proposed an alternative view of EBD, exploring how the concept of EBD supports better value generation for end-users. It presents the starting point of our research in this area, an exercise in critical reflection and appraisal and a holistic view of EBD integration that supports value generation which will be a promising area for healthcare building research. From the design point of view, the research takes an integrated approach of the built environment (hospital), seeking to explain the impacts of the environment on human well-being and performance. From the end-user point of view, the research looks at design strategies with the intention to maximize the occupants' benefits and minimize buildings' maintenance and management. As this study is still at the initial stage, it is limited to a conceptual approach that still has to be explored in a qualitative/quantitative empirical setting. Also, when collecting evidence that can make a difference to end users, some factors have a negative or positive impact; some have to take into consideration trade-offs in order to maximize environmental benefits. Therefore, the review may have been over-simplified when only positive impact was included in. Despite this, it makes a contribution to EBD research and its better links to value generation as a concept, by focusing on the enduser perspective. It raises issues about the nature of how EBD helps to increase the user value and offers an understanding of the future research necessary to support healthcare building and built environment at the design stage.

\section{REFERENCES}

Arthur, R. and Passini, R. (1992) Wayfinding: People, signs and architecture, McGrawHill, New York.

Barlas, D., Sama, A. E., Ward, M. F., \& Lesser, M. L. (2001). Comparison of the auditory and visual privacy of emergency department treatment areas with curtains versus those with solid walls. Annals of emergency medicine, 38(2), 135-139.

Carpman, J. \& Grant. M (2002). "Wayfinding: A Broad View," in Bechtel \& Churchman,eds., Handbook of Environmental Psychology. (pp. 427-442), New York: John Wiley \& Sons.

CDC and HICPAC. (2003). Guidelines for Environmental Infection Control in Healthcare Facilities. Atlanta, GA: Centers for Disease Control and Prevention and Healthcare Infection Control Practices Advisory Committee (HICPAC), 71-88. 
Cooper-Marcus, C., and M. Barnes (1995) Gardens in Healthcare Facilities. Concord, CA: The Center for Health Design.

Crane, B., Goodworth, A. D., Liquori, M., Ghosh, S., Certo, C., \& McCafferty, L. (2014). Multidisciplinary Testing of Floor Pads on Stability, Energy Absorption, and Ease of Hospital Use for Enhanced Patient Safety. Journal of patient safety.

Daykin, N., Byrne, E., Soteriou, T., \& O'Connor, S. (2008). Review: The impact of art, design and environment in mental healthcare: a systematic review of the literature. The Journal of the Royal Society for the Promotion of Health, 128(2), 85-94.

DiCenso A, Bayley L, Haynes RB. (2009) Accessing pre-appraised evidence: fine-tuning the 5S model into a 6S model. Evidence-Based Nursing, 12(4):99-101

Dijkstra, K., M. E. Pieterse, and A. Pruyn. 2008. "Stress-Reducing Effects of Indoor Plants in the Built Healthcare Environment: The Mediating Role of Perceived Attractiveness." Preventive Medicine 47 (3): 279-283.

Douglas, C. H., \& Douglas, M. R. (2004). Patient-friendly hospital environments: exploring the patients' perspective. Health Expectations, 7(1), 61-73.

Durmisevic S, Ciftcioglu Oे. Knowledge modeling tool for evidence-based design. HERD: Health Environments Research \& Design Journal. 2010 Apr 1;3(3):101-23.

Fontaine, K., L. Briggs, and B. Pope-Smith. 2001. "Designing Humanistic Critical Environments." Critical Care Nursing Quarterly 24 (3): 21-34.

Freedman NS, Gazendam J, Levan L, Pack AI, Schwab RJ. (2001) Abnormal sleep/wake cycles and the effect of environmental noise on sleep disruption in the intensive care unit. Am J Respir Crit Care Med 2001;163:451-7.

Grazier, K. L. (1999). Collaboration and quality in managed care. Journal of Healthcare Management, 44(3), 163.

Harris, D. D., \& Fitzgerald, L. (2015). A life-cycle cost analysis for flooring materials for healthcare facilities. Journal of Hospital Administration, 4(4), p92.

Hendrich, A. L., Fay, J., \& Sorrells, A. K. (2004). Effects of acuity-adaptable rooms on flow of patients and delivery of care. American Jo. of Critical Care, 13(1), 35-45.

Kaldenberg, D. O. (1999). The influence of having a roommate on patient satisfaction. The Satisfaction Monitor.

Kirk, S. (2002). Patient preferences for a single or shared room in a hospice. Nursing Times,98(50), 39-41.

Koskela, L., Howell, G., Ballard, G., \& Tommelein, I. (2002). The foundations of lean construction. Design and Construction: Building in Value. Oxford, UK: Butterwort.

Koskela, L. (2000). "An Exploration towards a Production Theory and its Application to Construction”. PhD Dissertation, VTT Building Technology, Espoo, Finland. 296 pp., VTT Publications: 408, ISBN 951-38-5565-1; 951-38-5566-X

Li, Y., G. M. Leung, J. W. Tang, X. Yang, C. Y. Chao, J. Z. Lin, J. W. Lu, et al. 2007. "Role of Ventilation in Airborne Transmission of Infectious Agents in the Built Environment - a Multi-Disciplinary Systematic Review. ”Indoor Air 17 (1): 2-18.

Marcus, C. C., \& Barnes, M. (1999). Healing gardens: Therapeutic benefits and design recommendations. John Wiley \& Sons.

Monitor (2015) Moving healthcare closer to home: Case studies, Monitor (September 2015) Publication code: IRRES 09/15, London, SE1 8UG

NHS Estates. (2005). Ward layouts with single rooms and space for flexibility. The Stationery Office.

Pati, D. (2011). A framework for evaluating evidence in evidence-based design. HERD: Health Environments Research \& Design Journal, 4(3), 50-71. 
Popay J. (2005) Moving beyond floccinaucinihilipilification: enhancing the utility of systematic reviews. Journal of Clinical Epidemiology 2005; 58: 1079-1080

Porter, M. E. (2010). What is value in health care? New England Journal of Medicine, 363(26), 2477-2481.

Raanaas, R. K., Patil, G. G., \& Hartig, T. (2012). Health benefits of a view of nature through the window: a quasi-experimental study of patients in a residential rehabilitation center. Clinical rehabilitation, 26(1), 21-32.

Rybkowski, Z.K. \& Ballard, G. (2008), Using the "Five Whys" as a Decision-Making Framework for Evidence-Based Design' In:16th Annual Conference of IGLC. Manchester, UK, 16-18 Jul 2008. pp 391-402

Salonen, H., Lahtinen, M., Lappalainen, S., Nevala, \& Reijula, K. (2013). Physical characteristics of the indoor environment that affect health and wellbeing in healthcare facilities: A review. Intelligent Buildings International, 5(1), 3-25.

Sheahan, M., Reading, M., \& Naccarella, L. (2016). Time out for nurses, Designing staff spaces in hospitals for work, rest and learning, HASSELL ,Melbourne VIC Australia 3000

Shewhart, W.A. (1931) Economic Control of Quality of Manufactured Product (New York: Van Nostrand).

Springer, T. (2007). Ergonomics for Healthcare Environments. Knoll: HERO, Inc.

Stichler JF. Creating healing environments in critical care units. Critical care nursing quarterly. 2001 Nov 1;24(3):1-20.

Tzortzopoulos P.; Chan, P.; Kagioglou, M.; Cooper, R.; Dyson, E. (2005) Interactions between transformations, flow and value at the design front-end for Primary Healthcare Facilities. In: $13^{\text {th }}$ IGLC, Sidney, Australia, July 2005, pp307-316

Uebele, A. 2007. Signage Systems and Information Graphics. New York, NY: Thame

Ulrich, R. S., Zimring, C., Zhu, X., DuBose, J., Seo, H. B., Choi, Y. S., ... \& Joseph, A. (2008). A review of the research literature on evidence-based healthcare design. HERD: Health Environments Research \& Design Journal, 1(3), 61-125.

van de Glind, I., de Roode, S., \& Goossensen, A. (2007). Do patients in hospitals benefit from single rooms? A literature review. Health Policy, 84(2), 153-161.

Walch et al. (2005). Effect of Sunlight on Postoperative Analgesic Medication Use:A Prospective Study of Patients Undergoing Spinal Surgery,Psycho Medi 67:156-163).

Zborowsky, T., Bunker-Hellmich, L., Morelli, A., \& O'Neill, M. (2010). Centralized vs. decentralized nursing stations: Effects on nurses' functional use of space and work environment. HERD: Health Environments Research \& Design Journal, 3(4), 19-42.

Zeithaml, V. A. (1988). Consumer perceptions of price, quality, and value: a means-end model and synthesis of evidence. The Journal of marketing, 2-22

Zhang, Y., Tzortzopoulos , P. \& Kagioglou, M. 2016, 'Evidence-Based Design in Healthcare: A Lean Perspective With an Emphasis on Value Generation' In:, $24^{\text {th }}$ IGLC. Boston, USA, 20-22 Jul 2016. 